ventricular output. Am. J. Obstet. Gynecol., 124: 183 (1976).

19. Silman, R. E., Chard T., Lowry, P. J., Smith, I., and Young, I. M.: Human foetal pituitary peptides and parturition. Nature, 260: 716 (1976).

20. Silman, R. E., Holland, D., Chard, T., Lowry, P. J., Hope, J., Robinson, J. S., and Thornburn, G. D.: The ACTH "family tree" of the rhesus monkey changes with development. Nature, 276: 526 (1978).

21. Silman, R. E., Holland, D., Chard, T., Lowry, P. J., Hope, J., Rees, L. H. Thomas, A., and Nathanielsz, P.: Adrenocorticotropin-related peptides in adult and foetal sheep pituitary glands. J. Endocrinol., 81: 19 (1979).

22. Winer, B. J.: Statistical principles in experimental design. pp. 261 (New York:McGraw-Hill Book Company, 1971).

23. Dr. Llanos is a recipient of a Postdoctoral Fellowship from the Bay Area Heart Research Association. His present address: Departmento de Ciencias Preclinicas, Division Oriente, Facultad de Medicina, Universidad de Chile, Casilla 16038, Santiago 9, Chile.
24. This work was partially presented at the 26th Annual Meeting of the Society for Gynecological Investigation, San Diego, USA, March 1979, and at the 17th Annual Meeting of the Latin American Society for Pediatric Research, Puerto Iguazu, Argentina, November, 1979.

25. We thank Dr. Barry Block for his assistance in writing the computer program utilized in the statistical analysis of the data. We thank Ms. Christine Roman and Mr. Carl McWatters for their skillful technical assistance and Ms. Mimi Zieger and Ms. Claudia Bello for their editorial assistance.

26. Requests for reprints should be addressed to: Dr. Michael A. Heymann, 1403 HSE, University of California, San Francisco, CA 94143.

27. This work was supported by grants from the U.S. Public Health Service: HD 06619, HL 06285, CA 16417.

28. Received for publication August 10, 1982

29. Accepted for publication March 24, 1983.

\title{
Regional Cerebral Blood Flow, Cerebral Blood Velocity, and Pulsatility Index in Newborn Dogs
}

\author{
DANIEL G. BATTON, ${ }^{(37)}$ JONATHAN HELLMANN, MILTON J. HERNANDEZ, AND \\ M. JEFFREY MAISELS \\ Division of Newborn Medicine, Department of Pediatrics, The Division of Neurology, Department of Medicine, \\ The Milton S. Hershey Medical Center of The Pennsylvania State University, College of Medicine, \\ Hershey, Pennsylvania, USA
}

\begin{abstract}
Summary
A technique employing a Doppler ultrasound probe to measure cerebral blood velocity was used to study the cerebral circulation continuously in $\mathbf{3 0}$ newborn mongrel dogs. Utilizing a transfontanelle approach, the probe was maintained in fixed position throughout a given experiment. In 20 animals, changes in systolic, diastolic, and mean cerebral blood velocity during hypo- and hypercarbia were directly correlated $(P<0.01)$ with changes in regional cerebral blood flow ( $\mathrm{rCBF}$ ) determined in 12 regions of the brain by the $\left[{ }^{14} \mathrm{C}\right]$ iodoantipyrine autoradiography technique. In an additional 10 dogs, multiple determinations of systolic, diastolic, and mean blood velocity were made over a wide range of $\mathrm{PaCO}_{2}$ values and found to be directly related to the $\mathrm{PaCO}_{2}(P$ $<0.001)$. These data suggest that changes in cerebral blood velocity are closely related to changes in cerebral blood flow. We also calculated the pulsatility index (PI) from the peak systolic and end diastolic velocities and found a poor, but direct $(r=0.28$, $P<0.05$ ) relationship between the $\mathrm{PI}$ and $\mathrm{PaCO}_{2}$ rather than the indirect relationship, which has been suggested in published clinical studies. We conclude that the Doppler technique may be valuable in monitoring dynamic events of the neonatal cerebral circulation if a constant probe position is maintained. Our results suggest, however, that the PI is not a reliable index of cerebral vascular resistance.
\end{abstract}

\section{Abbreviations}

AUTC, area under the curve

CBF, cerebral blood flow

rCBF, regional cerebral blood flow

CVR, cerebral vascular resistance

PI, pulsatility index
Currently there is no acceptable noninvasive method of assessing instantaneous changes in CBF in human newborns. The experimental methods for determining CBF in animals using electromagnetic flowmeters (21), radioactive tracers (31), and microspheres (30) clearly are not adaptable to humans. The injection or inhalation of radioactive xenon has been used in human adults $(13,22)$ and newborns $(19,20)$, although its use in infants is limited because the technique is invasive and involves a radioactive substance. Occlusion plethysmography in newborn infants, although noninvasive, includes extracranial as well as intracranial blood flow $(4,5,17)$. With all of these methods only single or intermittent determinations can be made, and instantaneous changes in CBF cannot be determined.

Recently, transcutaneous Doppler ultrasound has been used to study the cerebral circulation in human adults $(8,28)$ and newborns (1) by determining changes in blood velocity. The advantages of this technique are that it is noninvasive and provides continuous information. Its limitations include the difficulty of standardizing the angle between the Doppler probe and the blood vessel, and defining the relationship between blood velocity and blood flow.

Bada et al. (1) were the first investigators to recognize the value of Doppler ultrasound in monitoring cerebral hemodynamics through the open anterior fontanelle in the human newborn. They attempted to minimize the Doppler's limitations by calculating the PI, rather than determining blood velocity directly. The PI is thought to be an index of CVR and, because it is a ratio, is less affected by probe position $(1,27)$. Despite several clinical studies utilizing the concept of PI in newborn infants $(6$, $11,12,15,18,23,24-26,29)$, the validity of this technique has not yet been confirmed.

In this study, we utilized newborn dogs to evaluate the transfontanelle Doppler method for determining cerebral blood ve- 
locity while simultaneously determining $\mathrm{rCBF}$ by an autoradiographic technique. In addition, the PI was calculated and its validity examined during measured changes in cerebral vascular resistance.

\section{MATERIALS AND METHODS}

Thirty newborn mongrel dogs $1-12$ days of age and weighing 271-838 g were used for these studies. After light halothane anesthesia, each dog was rapidly tracheostomized, paralyzed with pancuronium bromide, and mechanically ventilated with a mixture of $70 \%$ nitrous oxide and $30 \%$ oxygen. Halothane was used for less than $10 \mathrm{~min}$ and no determinations of rCBF or blood velocity were made within $1 \mathrm{~h}$ of its use. Ventilatory rate and tidal volume were adjusted initially to obtain normal arterial blood gases. A femoral artery was cannulated for continuous measurement of arterial blood pressure and for obtaining blood samples for the determination of $\mathrm{pH}, \mathrm{PaCO}_{2}$, and $\mathrm{PaO}_{2}$. The other femoral artery was cannulated for collection of blood samples for $\mathrm{rCBF}$ determination. A femoral venous catheter was placed into the inferior vena cava for infusion of $\left[{ }^{14} \mathrm{C}\right]$ iodoantipyrine. Temperature was continuously monitored by means of a rectal thermocouple and maintained at $37^{\circ} \mathrm{C}$ by means of a heat lamp.

Each dog was placed prone in a stereotaxic frame and a small longitudinal scalp incision was made over the anterior fontanelle to expose the skull. A 5.0 MHz probe transducer from a PARKS 909 bidirectional Doppler ultrasound unit (Parks Electronics Laboratory, Beaverton, OR) was positioned just above the fontanelle, directed anteriorly at approximately a $60^{\circ}$ angle to the horizontal and laterally to avoid contamination by the sagittal sinus. By assessing the auditory and visual Doppler signals, the probe position was then adjusted slightly to allow recording of a single arterial velocity wave form with the direction of blood flow being towards the probe. We cannot be certain which vessel we were monitoring, but based on probe position and direction of blood flow, it is likely this was the anterior cerebral artery coursing superior to the corpus callosum. Although the anterior fontanelle in the newborn dog is closed, the thin skull bones allow for Doppler recordings of good quality. While the precise angle between the probe and vessel was unknown, the animals' head and probe were secured, and remained in fixed position for the duration of a given experiment. The systolic and diastolic velocities were calculated by averaging 10 consecutive peak systolic and end-diastolic velocities respectively, whereas mean velocity was determined by electrical integration of the wave form.

CBF was determined by an autoradiographic technique (10, 31). $\left[{ }^{14} \mathrm{C}\right]$ Iodoantipyrine was infused into the inferior vena cava at a constant rate over $60 \mathrm{sec}$ while drops of femoral artery blood were collected at 5 -sec intervals. When the infusion was completed the circulation was stopped by a bolus infusion of $\mathrm{KCl}$ through the femoral venous catheter. The brain was then removed and frozen in Freon 12. Sections of brain, $50 \mu \mathrm{m}$ thick, were cut in a cryostat, placed on glass slides, dried, and applied to single emulsion mammography film. After the autoradiograms were developed, rCBF was determined for 12 regions of the brain from readings of optical densities as compared to standards.

Twenty animals were used to examine changes in cerebral blood velocity, PI, and rCBF during hypo- and hypercarbia. In seven control dogs, rCBF was measured after the respirator was adjusted to maintain a steady state of normal arterial blood gases. In six dogs, the ventilatory rate was increased to produce hypocarbia. At least $15 \mathrm{~min}$ were allowed for stabilization of $\mathrm{PaCO}_{2}$ between rate changes. In these animals, recordings of systolic, diastolic, and mean arterial blood velocities were made at both the control (normocarbic) and final (hypocarbic) $\mathrm{PaCO}_{2}$ levels. At the final level of ventilation, $\mathrm{rCBF}$ was also determined by the autoradiographic technique. In a third group of seven dogs, cerebral blood velocity and $\mathrm{rCBF}$ were determined during hypercarbia produced by decreasing the ventilatory rate.
In order to evaluate further the relationship between cerebral blood velocity and $\mathrm{PI}$ with changes in arterial $\mathrm{CO}_{2}$ tension, multiple determinations were made at different $\mathrm{PaCO}_{2}$ levels in 10 dogs. Ventilatory rate and tidal volume were first adjusted to obtain arterial normocarbia and the dogs allowed to stabilize. The ventilatory rate was then periodically adjusted inducing various degrees of hypo- and hypercarbia. A stabilization period of at least $15 \mathrm{~min}$ was allowed at each level of ventilation. Systolic, diastolic, and mean blood velocities were recorded for 5-12 different $\mathrm{PaCO}_{2}$ levels in each experimental animal.

The PI was then calculated according to Pourcelot (27) from the peak systolic (S) and end-diastolic (D) blood velocities as follows:

$$
\mathrm{PI}=\frac{\mathrm{S}-\mathrm{D}}{\mathrm{S}}
$$

Because the angle of the transducer probe with the vessel axis was not known but remained constant, relative, but not absolute, changes in blood velocity could be determined and data are therefore presented in terms of $\%$ change from control values. The data were analyzed statistically using linear regression, paired and unpaired $t$ tests where appropriate.

\section{RESULTS}

The mean arterial $\mathrm{pH}, \mathrm{PaCO}_{2}, \mathrm{PaO}_{2}$, and blood pressures for the 20 dogs in which cerebral blood velocity was correlated with rCBF are listed in Table 1. Although blood pressure decreased significantly during hypocarbia, the magnitude of the change did not exceed the limits of $\mathrm{CBF}$ autoregulation established for newborn dogs, which have shown that with mean systemic pressures between 35-90 Torr, CBF is maintained at normal levels (9).

CBF was measured in 12 regions of the brain (Table 2). These values fall within the ranges that have previously been reported for anesthetized newborn dogs $(10,32)$. Although flow increased significantly during hypercarbia, the decrease during hypocarbia was not statistically significant. Regional cerebral vascular resistance was inversely related to $\mathrm{rCBF}$ and changed significantly during hypercarbia $(P<0.05)$ but not during hypocarbia.

The changes in systolic, diastolic, and mean blood velocity during hypo- and hypercarbia are shown in Figure 1. Values obtained during hypocarbia were significantly different from those during hypercarbia $(P<0.05)$. The correlation between changes in systolic blood velocity and $\mathrm{rCBF}$ in four representative regions of brain are depicted in Figure 2. Similar significant correlations were found for the other eight regions studied $(P<$ $0.01)$. In addition, mean and diastolic velocities also correlated significantly with $\mathrm{rCBF}(P<0.01)$. In contrast to the changes noted in blood velocity, the PI did not change significantly during hypo or hypercarbia $(P>0.05)$.

In the 10 animals in which multiple determinations of blood velocity and PI were made at various levels of ventilation, changes in systolic and diastolic blood velocity were found to be significantly and directly related to changes in $\mathrm{PaCO}_{2}$ (Fig. 3 and 4). Mean velocity was also directly related to $\mathrm{PaCO}_{2}(r=0.66, P$ $<0.001, \mathrm{y}=1.4+0.30 \mathrm{x})$. The relation between $\mathrm{PI}$ and $\mathrm{PaCO}_{2}$ is shown in Figure 5. Although statistically significant $(P<0.05)$,

Table 1. Physiologic data for 20 newborn dogs in which cerebral blood velocity was correlated with $r C B F^{1}$

\begin{tabular}{lccc}
\hline & $\begin{array}{c}\text { Control } \\
(n=7)\end{array}$ & $\begin{array}{c}\text { Hypocarbia } \\
(n=6)\end{array}$ & $\begin{array}{c}\text { Hypercarbia } \\
(n=7)\end{array}$ \\
\hline $\mathrm{pH}$ & $7.34 \pm 0.04$ & $7.40 \pm 0.04$ & $7.05 \pm 0.10^{2}$ \\
$\mathrm{PaCO}_{2}$ (torr) & $37 \pm 3$ & $22 \pm 3^{2}$ & $71 \pm 7^{2}$ \\
$\mathrm{PaO}_{2}$ (torr) & $112 \pm 18$ & $113 \pm 23$ & $76 \pm 10^{2}$ \\
$\mathrm{Mean} \mathrm{BP}^{2}$ (torr) & $70 \pm 14$ & $50 \pm 8^{2}$ & $68 \pm 12$ \\
\hline
\end{tabular}

\footnotetext{
${ }^{1}$ All data expressed as mean \pm S.D.
}

${ }^{2} P<0.01$ compared with control. 
Table 2. Regional cerebral blood flow ( $r C B F$ ) during normo-, hypo-, and hypercarbia ${ }^{1}$

\begin{tabular}{|c|c|c|c|c|c|}
\hline \multirow[b]{2}{*}{ Region } & \multirow{2}{*}{$\begin{array}{c}\text { Normocarbia } \\
\text { rCBF } \\
(\mathrm{cc} / 100 \mathrm{~g} / \mathrm{min}) \\
(n=7)\end{array}$} & \multicolumn{2}{|c|}{ Hypocarbia rCBF } & \multicolumn{2}{|c|}{ Hypercarbia rCBF } \\
\hline & & \multicolumn{2}{|c|}{$(n=6)$} & \multicolumn{2}{|c|}{$(n=7)$} \\
\hline Frontal cortex & $26 \pm 4$ & $27 \pm 6$ & +4 & $56 \pm 21^{3}$ & +115 \\
\hline Parietal cortex & $26 \pm 5$ & $25 \pm 7$ & -4 & $53 \pm 19^{3}$ & +104 \\
\hline Temporal cortex & $24 \pm 4$ & $21 \pm 4$ & -13 & $46 \pm 17^{3}$ & +92 \\
\hline Occipital cortex & $26 \pm 3$ & $23 \pm 6$ & -12 & $46 \pm 17^{3}$ & +77 \\
\hline Caudate nucleus & $25 \pm 5$ & $22 \pm 4$ & -12 & $49 \pm 18^{3}$ & +96 \\
\hline Corpus callosum & $14 \pm 4$ & $12 \pm 2$ & -14 & $34 \pm 13^{3}$ & +143 \\
\hline Subcortical white matter ${ }^{2}$ & $6 \pm 3$ & $6 \pm 1$ & 0 & $14 \pm 5^{3}$ & +133 \\
\hline Hippocampus & $22 \pm 4$ & $20 \pm 4$ & -9 & $44 \pm 16^{3}$ & +100 \\
\hline Thalamus & $35 \pm 5$ & $26 \pm 4^{3}$ & -27 & $67 \pm 25^{3}$ & +91 \\
\hline Hypothalamus & $30 \pm 6$ & $23 \pm 4$ & -23 & $65 \pm 22^{3}$ & +118 \\
\hline Inferior colliculi & $37 \pm 8$ & $28 \pm 5$ & -24 & $74 \pm 27^{3}$ & +100 \\
\hline Cerebellar vermis & $31 \pm 7$ & $24 \pm 6$ & -23 & $60 \pm 23^{3}$ & +94 \\
\hline
\end{tabular}

${ }^{1}$ All values expressed as mean \pm S.D.

${ }^{2}$ Includes periventricular, frontal, and occipital white matter.

${ }^{3} P<0.05$ compared with normocarbia.

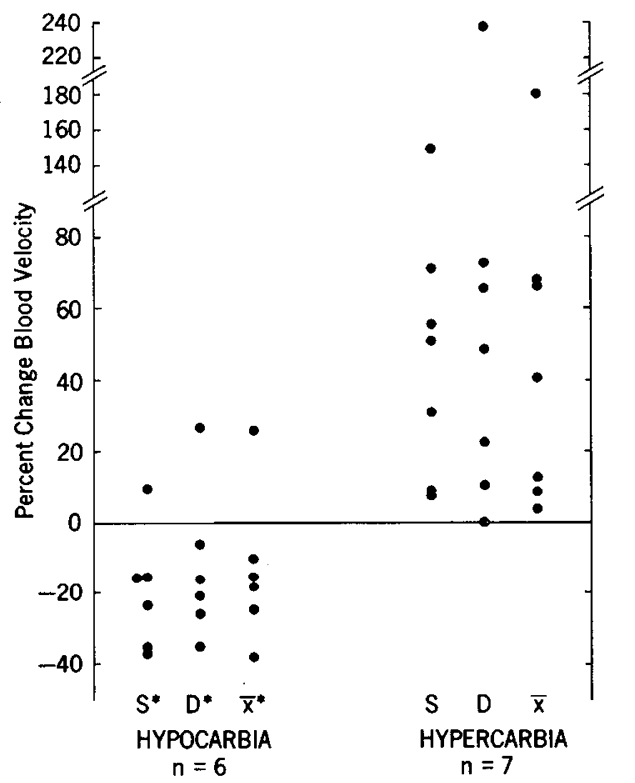

Fig. 1. Changes in systolic $(S)$, diastolic $(D)$, and mean $(\bar{x})$ blood velocity during hypo- and hypercarbia in 13 newborn dogs. ${ }^{*} P<0.05$ compared to hypercarbia.

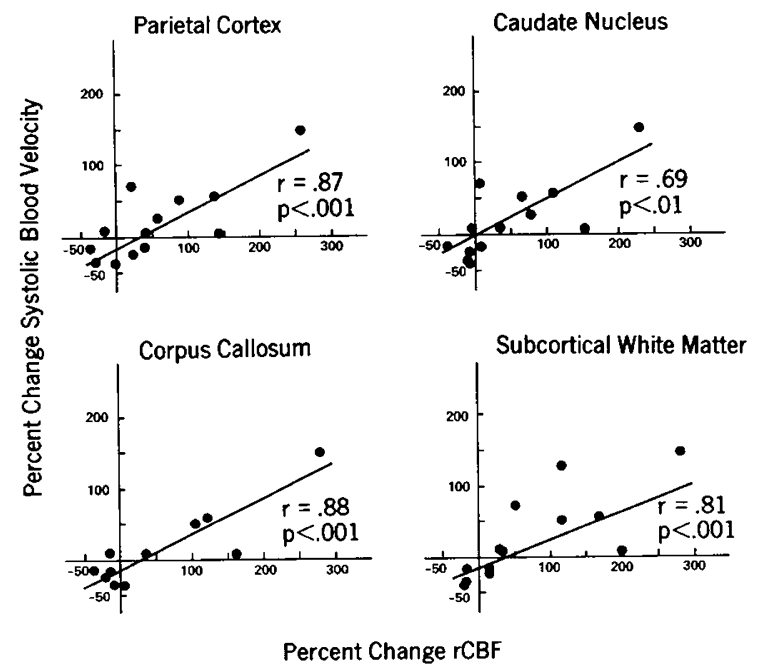

Fig. 2. Linear regression analysis of $\%$ change in systolic arterial blood velocity with \% change in regional cerebral blood flow ( $\mathrm{rCBF}$ ) in four representative brain regions.

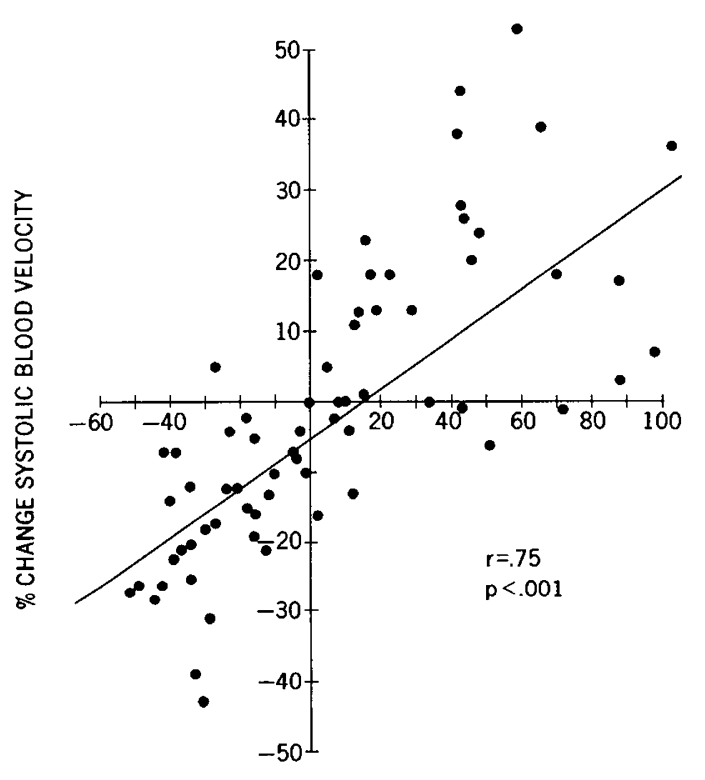

$\%$ CHANGE PaCO

Fig. 3. Linear regression analysis of $\%$ change in systolic arterial blood velocity with \% change in $\mathrm{PaCO}_{2}$ in 10 newborn dogs. $\mathrm{y}=-4.0+0.32 \mathrm{x}$.

the relationship is not strong $(r=0.28)$ and demonstrates a negative correlation betwen CVR and PI rather than the direct relationship suggested by various authors $(1,27)$.

\section{DISCUSSION}

The Doppler technique determines the frequency shift between emitted and received ultrasound as reflected from moving red blood cells $(7,14,33)$. This frequency shift is directly proportional to blood velocity, provided the angle between the Doppler probe and the blood vessel is either known or remains constant $(7,14,33)$. Blood velocity is proportional to blood flow if the cross sectional area of the blood vessel remains unchanged $(7$, 14, 33, 34). Despite these limitations, Hauge et al. (8) described a technique for determining changes in CBF by measuring the mean blood velocity transcutaneously in the internal carotid and vertebral arteries. Although the angle between the probe and the vessel could only be estimated, and the vessel diameter was not measured, a direct relationship was shown between blood velocity and $\mathrm{PaCO}_{2}$. Risberg and Smith (28) found significant correlations between end diastolic blood velocity in the internal carotid arteries and hemispheric $\mathrm{rCBF}$ using the $\left[{ }^{133} \mathrm{Xe}\right]$ inhalation 


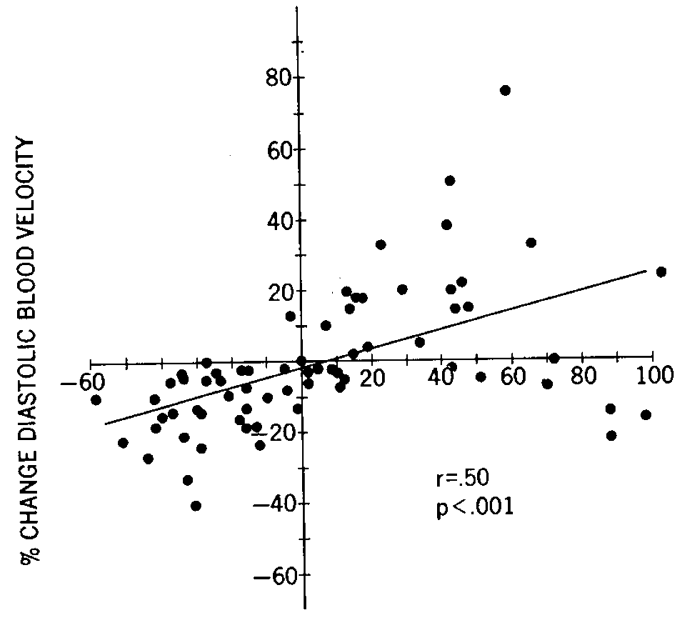

$\%$ CHANGE $\mathrm{PaCO}_{2}$

Fig. 4. Linear regression analysis of $\%$ change in diastolic arterial blood velocity with \% change in $\mathrm{PaCO}_{2}$ in 10 newborn dogs. $\mathrm{y}=-1.4+$ $0.25 \mathrm{x}$.

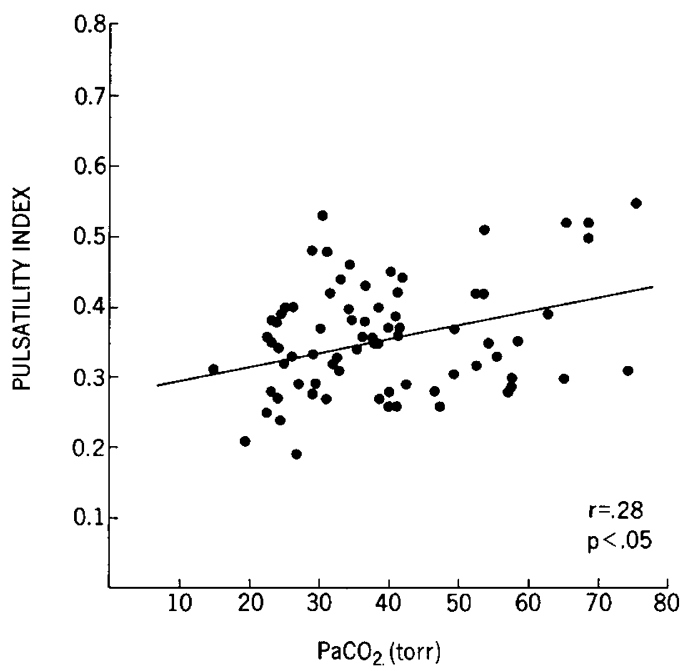

Fig. 5. Linear regression analysis of pulsatility index (PI) with $\mathrm{PaCO}_{2}$ in 10 newborn dogs.

method, even though the probe angle and vessel diameter were not accurately known. Busija et al. (3) have measured directly the diameter of pial arterioles during hypo- and hypercarbia in animals, and measured blood velocity while keeping the probe angle constant. A good correlation was found between this method and the microsphere method for determining changes in CBF.

Our study further supports the idea that Dopplers can be used to assess continuous changes in CBF. We have shown that, if the probe angle remains constant, changes in systolic, diastolic, and mean blood velocity are directly related to changes in $\mathrm{rCBF}$ when $\mathrm{PaCO}_{2}$ is altered. The mean velocity is an integrated mean as determined by electrical integration of the wave form and we have confirmed that this closely corresponds $(r=0.99)$ to the AUTC as determined by planimetry. AUTC has been suggested by Rosenkrantz and Oh (29) to correlate well with blood flow. But as they have pointed out, AUTC is dependent on probe angle as are systolic and diastolic velocity; therefore, for this technique to be useful and reliable in human newborns, it is necessary to establish reasonable consistency of the probe angle with the blood vessel.

It is not clear why rCBF changed less during hypocarbia than during hypercarbia. Although flow tended to decrease, the hypocarbic insult was not sufficient to produce a statistically significant reduction in flow. Shapiro et al. (32) have also shown insignificant changes in $\mathrm{rCBF}$ in newborn dogs during similar degrees of hypocarbia. They have proposed that the newborn has a lower $\mathrm{CO}_{2}$-sensitivity during hypocarbia than during hypercarbia. Our results tend to support this idea.

We have also shown that under our experimental conditions the PI is not a direct index of CVR as previously contended. The PI has been thought to be an index of vascular resistance based on the assumption that it is largely the diastolic rather than systolic blood velocity that is affected by changes in cerebral vascular resistance $(1,27)$. A decreased diastolic velocity (which would increase the calculated PI) indicates increased CVR, and conversely an increased diastolic velocity suggests decreased CVR; thus, according to Pourcelot (27) and others (1), PI and CVR are thought to be directly related. It should be noted that Pourcelot's studies were done on the carotid arteries in adults with peripheral vascular disease. The hemodynamics in this situation cannot be assumed to be comparable to intracerebral hemodynamics in premature infants. Furthermore, there have been no previous studies correlating intracerebral PI with other methods of determining CVR. Our data suggest that PI and CVR are not directly related because systolic as well as diastolic velocity varies with $\mathrm{PaCO}_{2}$.

Since Bada's original description of changes in the PI among premature infants after intraventricular hemorrhage and asphyxia (1), several authors have reported a number of other factors which have been shown to affect the PI: pneumothorax (11), hydrocephalus (12), patent ductus arteriosus $(18,24)$, muscle relaxants (23), hypercarbia (6), alterations in blood pressure (15) hyperviscosity (29), seizures (26), and endotracheal tube suctioning (25). Because many of these factors are likely to be present in the same patient population (premature infants with respiratory distress), it is difficult to attribute a change in PI to any single variable.

The limitations of the Doppler method of PI determination in newborn infants have recently been reviewed by Bejar et al. (2) and Vope et al. (35). As they have emphasized, the PI, although independent of probe angle, is not a measure of blood flow nor is it a direct measure of blood velocity. By definition, a change in the PI only reflects a change in the difference between the systolic and diastolic velocities; however, unless the probe position has been consistent it is impossible to state whether the PI has changed because of a change in the systolic or the diastolic velocity despite the graphic appearance of the Doppler wave form.

In conclusion, we have shown that the Doppler technique can be used through the closed anterior fontanelle in newborn dogs under controlled experimental conditions to determine instantaneous changes in blood velocity that are directly related to changes in CBF. We have also shown that the PI is not directly related to CVR; thus, the hemodynamic significance of alterations in the PI in human newborns remains to be delineated. Pending further clarification of the significance of the PI, we suggest future clinical studies determine changes in systolic, diastolic, and mean (AUTC) blood velocity, and be done with a method that assures consistency of the probe angle between sequential measurements.

\section{REFERENCES AND NOTES}

1. Bada, H. S., Hajjar. W., Chua, C., and Sumner, D. S.: Noninvasive diagnosis of neonatal asphyxia and intraventricular hemorrhage by Doppler ultrasound. J. Pediatr., 95: 775 (1979).

2. Bejar, R, Merritt, T. A.. Coen, R. W. Mannino, F., and Gluck, L.: Pulsatility index, patent ductus arteriosus, and brain damage. Pediatrics, 69: 818 (1982).

3. Busija, D. W., Heistad, D. D.. and Marcus, M. L.: Continuous measurement of cerebral blood flow in anesthetized cats and dogs. Am. J. Physiol 24I(Heart Circ. Physiol. 10): H228 (1981).

4. Cooke, R. W. L., Costeloe, K., Rolfe, R., and Howat, P.: Measurement of Cerebral Blood Flow in the Newborn. In: Stern L., Oh W.. and Friis-Hansen B.: Intensive Care in the Newborn, II. p. 127. (Masson Publishing USA, Inc., New York, 1978).

5. Cross. K. W. Dear, P. R. F. Hathorn, M. K. S., Hyams, S. A., McK. Kerslake D., Milligan, D. W. A., Rahilly, P.M., and Stothers, J.K.: An estimation of intracranial blood flow in the newborn infant. J. Physiol. 289: 329 (1979).

6. Daven, J., Milstein, J., and Guthrie, R.: Cerebral vascular resistance in sick premature infants. Ann. Neurol. (Abstract), 8: 213 (1980).

7. Grossman, B. L. and Wood, E. H.: Doppler ultrasonic evaluation of extracra- 
nial cerebrovascular disease. In: Recent Advances in the Study of Cerebral Circulation. Tarases J. M., Fischgold H., and Dilenge D., (eds) pp. 175 (Charles C. Thomas, Springfield, IL, 1980).

8. Hauge, A., Thoresen, M., and Walloe, L.: Changes in cerebral blood flow during hyperventilation and $\mathrm{CO}_{2}$-breathing measured transcutaneously in humans by a bidirectional, pulsed, ultrasound doppler blood velocitymeter. Acta Physiol. Scand., 110:167 (1980).

9. Hernandez, M. J., Brennan, R. W., and Bowman, G. S.: Autoregulation of cerebral blood flow in the newborn dog. Brain Res., 184: 199 (1980).

10. Hernandez, M. J., Brennan, R. W., and Hawkins, R. A.: Regional cerebral blood flow during neonatal asphyxia. In: Passoneau J. V., Hawkins R. A. Lust W. D., Welsh F. A.: p. 196 (Williams and Wilkins, Baltimore, 1980).

11. Hill, A., Perlman, J. M., and Volpe, J. J.: Relationship of pneumothroax to occurrence of intraventricular hemorrhage in the premature newborn. Pediatrics, 69: 144 (1982).

12. Hill, A. and Volpe, J. J.: Decrease in pulsatile flow in the anterior cerebral arteries in infantile hydrocephalus. Pediatrics, 69: 4 (1982).

13. Hoedt-Rasmussen, K., Sveinsdottir, E., and Lassen, N. A.: Regional cerebral blood flow in man determined by intra-arterial injection of radioactive inert gas. Circ. Res., I8: 237 (1966)

14. Joyner, C. R.: Transcutaneous Doppler detector in the study of arterial and venous flow patterns. Cardiovasc. Clin., 6(3): 385 (1975).

15. Karickhoff, A.: Simultaneous blood pressure and anterior cerebral artery flow velocity wave form analysis in the preterm infant. Pediatr. Res. (Abstract). 15: 666 (1980).

16. Kennedy, C., Grave, G. D., Jehle J. W., and Sokoloff, L.: Changes in blood flow in the component structures of the dog brain during postnatal maturation. J. Neurochem. 19: 2423 (1972).

17. Leahy, F. A. N. Sankaran, K. Cates, D., MacCallum, M., and Rigatto, H. Quantitative noninvasive method to measure cerebral blood flow in newborn infants. Pediatrics, 64: 277 (1979)

18. Lipman, B., Serwer, G., and Brazy, J. E.: Abnormal cerebral hemodynamics in preterm infants with patent ductus arteriosus. Pediatrics, 69:778 (1982)

19. Lou, H. C., Lassen, N. A., and Friis-Hansen, B.: Impaired autoregulation of cerebral blood flow in the distressed newborn infant. J. Pediatr., 94: 118 (1979)

20. Ment, L. R., Ehrenkranz, E. R., Lange, R. C., Rothstein, P. T., and Duncan, C. C.: Alterations in cerebral blood flow in preterm infants with intraventricular hemorrhage. Pediatrics, 68: 763 (1981).

21. Mills, C. J.: Measurement of pulsatile flow and flow velocity. In: Bergel D. H.: Cardiovascular Fluid Dynamics. Vol. 1, p. 51. (Academic Press, Inc. London, 1972).

22. Obrist, W., Thompson, H. K., King, H., and Wang, H.: Determination of regional cerebral blood flow by inhalation of 133-Xenon. Circ. Res., 20: 124 (1967).

23. Peabody, J. L.: Mechanical ventilation of the newborn: ... Good news ... bad news. Crit. Care Med., 9:710 (1981).

24. Perlman, J. M., Hill, A., and Volpe, J. J.: The effect of patent ductus arteriosus on flow velocity in the anterior cerebral arteries: Ductal steal in the premature newborn infant. J. Pediatr., 99: 767 (1981).

25. Perlman, J. M. and Volpe. J. J.: The effects of oral suctioning and endotracheal suctioning on cerebral blood flow velocity and intracranial pressure in the preterm infant. Pediatr. Res. (Abstract) I6(4): 303A (1982).

26. Perlman, J. M. and Volpe, J. J.: The effects of seizures on cerebral blood flow velocity, intracranial pressure, and systemic blood pressure in the preterm infant. Pediatr. Res.. (Abstract) 16(4): 339A (1982).

27. Pourcelot, L.: Applications cliniques de l'examen Doppler transcutane. In: Peronneau P. Velocimetre Ultrasonore Doppler. p. 213. (INSERM, Paris, 1975).

28. Risberg, J. and Smith, P.: Prediction of hemispheric blood flow from carotid velocity measurements. Stroke, 11: 399 (1980).

29. Rosenkrantz, T. S. and Oh, W.: Cerebral blood flow velocity in infants with polycythemia and hyperviscosity: efects of partial exchange transfusion with plasmanate. J. Pediatr., 101: 94 (1982).

30. Rudolph, A. M. and Heymann, M. A.: The circulation of the fetus in utero. Circ. Res., 21: 163 (1967).

31. Sakurada. O. Kennedy, C. Jehle, J., Brown, J. D. Carbin G. L and Sokoloff, L. Measurement of local cerebral blood flow with iodo $\left[{ }^{14} \mathrm{C}\right]$ antipyrine. $\mathrm{Am}$. J. Physiol.. 234(I): H59 (1978).

32. Shapiro, H. M., Greenberg, J. H., Van Horn Naughton, K., and Reivich, M.: Heterogeneity of local cerebral blood flow- $\mathrm{PaCO}_{2}$ sensitivity in neonatal dogs. J. Appl. Physiol. 49(1): 113 (1980).

33. Strandness, D. E.: The use of ultrasound in the evaluation of peripheral vascular disease. Prog. Cardiovasc. Dis., 20:403 (1978).

34. Uematsu, S.: Determination of volume of arterial blood flow by an ultrasonic device J Clin. Ultrasound, 9:209 (1981).

35. Volpe, J. J., Perlman, J. M., Hill, A., and McMenamin, J. B.: Cerebral blood flow velocity in the human newborn: the value of its determination. Pediatrics, 70: 147 (1982)

36. The authors wish to thank Elizabeth Nardis for her expert technical assistance with this study.

37. Requests for reprints should be addressed to: Dr. Daniel Batton, Department of Pediatrics, The M. S. Hershey Medical Center, Hershey, PA 17033.

38. Received for publication September 14, 1982

39. Accepted for publication March 25, 1983.

\title{
Distribution of Trace Elements and Minerals in Human and Cow's Milk
}

\author{
GUN-BRITT FRANSSON ${ }^{(37)}$ AND BO LÖNNERDAL ${ }^{(38,40)}$ \\ Institute of Nutrition, University of Uppsala, Sweden and Department of Nutrition, University of California, \\ Davis, California, USA
}

\section{Summary}

The concentration of iron in cow's milk, $0.40-0.59 \mu \mathrm{g} / \mathrm{ml}$, was found to be very similar to that of human milk, $0.20-0.69 \mu \mathrm{g} / \mathrm{ml}$. The copper concentration of cow's milk $(0.06-0.09 \mu \mathrm{g} / \mathrm{ml})$ is lower than in human milk $(0.24-0.50 \mu \mathrm{g} / \mathrm{ml})$ whereas the concentration of zinc is higher in cow's milk $(3.23-5.15 \mu \mathrm{g} / \mathrm{ml})$ than in human milk (1.16-3.83 $\mu \mathrm{g} / \mathrm{ml})$. Cow's milk contains about 4 5 times more calcium and magnesium, 854-1430 $\mu \mathrm{g} / \mathrm{ml}$ and $87-131 \mu \mathrm{g} / \mathrm{ml}$, respectively, than human milk $(220-252 \mu \mathrm{g} / \mathrm{ml}$ and $26-35 \mu \mathrm{g} / \mathrm{ml})$. Cow's milk was fractionated and the trace element and mineral contents of the different fractions were compared to results from human milk. The casein fraction in cow's milk contains a large proportion of the total amounts of the elements cited above (Fe 24\%, $\mathrm{Cu} \mathrm{44 \% ,} \mathrm{Zn} \mathrm{84 \% ,} \mathrm{Ca} 41 \%$, $\mathrm{Mg} \mathbf{2 5 \%}$ ) whereas human casein only binds minor amounts (Fe $9 \%, \mathrm{Cu} \mathrm{7 \% ,} \mathrm{Zn} \mathrm{8 \% ,} \mathrm{Ca} \mathrm{6 \% ,} \mathrm{Mg} \mathrm{6 \% ).} \mathrm{Whey} \mathrm{proteins} \mathrm{bind} \mathrm{a}$ major part of these elements in human milk, but not in cow's milk. Significant amounts of iron are bound to the lipid fraction in both cow's and human milk (14 and 33\%, respectively), predominantly bound to the outer fat globule membrane. Low molecular weight compounds (ligands) bind significant proportions of all the elements investigated in both cow's and human milk, with the exception of zinc in cow's milk, of which only $2 \%$ is associated with this fraction.

The differences in trace element bioavailability observed in 